\title{
Jargon dalam Tindak Tutur Waria Pekerja Salon Sandra Jalan Jawa Jember dalam Interaksi Sosial
}

\section{Jargon In The Speech Act Of Transgender Women Working At The Sandra Salon On Jalan Jawa Jember In Social Interactions}

\author{
Budi Utomo ${ }^{1}$ \\ Artikel diterima editor tanggal 09-03-2021, disetujui untuk dipublikasikan tanggal 29-05-2021 \\ Doi: $x x x x x-x x x x x$
}

\begin{abstract}
Abstrak
Di dalam masyarakat luas terdapat jargon yang digunakan oleh kelompok masayarakat tertentu. Di antara kelompok masyarakat itu adalah kelompok waria. Para waria menggunakan variasi bahasa yang disebut dengan jargon. Hal ini dilakukan untuk menutupi identitas dan aktivitas keseharian mereka yang cenderung menyimpang atau berbeda dengan masyarakat lainnya yang normal. Keadaan ini menarik untuk diteliti karena dengan penelitian, bisa diketahui bagaimana ragam bahasa berbentuk jargon yang digunakan oleh para waria dalam menyembunyikan rahasia-rahasia mereka agar tidak diketahui oleh masyarakat. Penelitian ini menggunakan metode kualitatif. Data diperoleh dari subjek yaitu dari para waria yang bekerja di salon Sandra jalan Jawa Jember yang kesehariannya menggunakan jargon dalam berkomunikasi dengan antarwaria bahkan terkadang dengan pelanggannya. Berdasarkan data, dapat disimpulkan bahwa jargon yang digunakan para waria pekerja salon Sandra jalan Jawa Jember berbentuk kata, singkatan atau akronim, dan berupa kalimat yang berfungsi untuk fungsi representatif, fungsi direktif, fungsi komisif, fungsi ekspresif, fungsi deklaratif, dan fungsi komunikatif.
\end{abstract}

Kata kunci: Jargon, tindak tutur, pekerja salon Sandra, interaksi sosial.

\begin{abstract}
In the wider community, there is jargon used by certain community groups. Among the community groups are transgender groups. Transgenders use a variety of language called jargon. This is done to cover their identity and daily activities that tend to deviate or differ from other normal people. This situation is interesting to study because, with research, it can be seen how the variety of jargon-shaped languages used by transgenders in hiding their secrets so that they are not known by the public. This study uses a qualitative method. Data were obtained from the subject, namely the transgender women who worked at the Sa ndra salon, Jalan Jawa Jember, who used jargon in their daily communication with transgender women and sometimes even with their customers. Based on the data, it can be concluded that the jargon used by the transgender workers at the Sandra Salon Jalan Jawa Jember is in the form of words, abbreviations, or acronyms, and in the form of sentences that function for representative functions, directive functions, commissive functions, expressive functions, declarative functions, and communicative functions.
\end{abstract}

Keywords: Jargon, speech acts, Sandra salon workers, social interactions

\footnotetext{
${ }^{1}$ Budi Utomo, SMA Negeri 2 Jember, budiida024@gmail.com
} 


\section{Pendahuluan}

Komunikasi dengan orang lain dibutuhkan dalam kehidupan kita. Komunikasi yang kita lakukan, bisa berupa bahasa tulis maupun bahasa lisan. Bahasa yang kita gunakan itu dapat berupa bahasa yang dikuasai manusia secara luas ataupun oleh kalangan tertentu saja. Manusia adalah makhluk individu dan makhluk sosial yang hidup berkelompok dan membutuhkan satu sama lain (Inah, 2013). Sebagai makhluk sosial, manusia membutuhkan alat komunikasi yang dapat diterima atau dimengerti oleh orang lain. Oleh karena itu, dalam tindakan sosial mesti terdapat beberapa elemen umum yang sama-sama disepakati dan dipahami oleh sejumlah masyarakat.

Agar terhubungnya sesama anggota masyarakat maka diperlukan alat komunikasi. Komunikasi adalah proses interaksi penyampaian pesan dari pengirim kepada penerima (Arifin, 1995). Komunikasi menyatukan para individu ke dalam kelompok-kelompok dengan jalan memelihara serta mengawetkan ikatan-ikatan kepentingan umum, membuat suatu kesatuan pada lambang-lambang yang membedakannya dari kelompok-kelompok lain, dan menetapkan suatu tindakan tersebut tidak akan ada, serta mampu bertahan lama tanpa adanya masyarakat-masyarakat bahasa.

Ujaran sebagai alat untuk berkomunikasi sangat memengaruhi kehidupan-kehidupan individual kita. Dalam sistem inilah kita saling bertukar gagasan, perasaan, pendapat keinginan dengan bantuan lambang-lambang yang disebut kata. Sistem inilah yang memberikan keefektifan bagi individu dalam menjalankan hubungan emosional dan mental dengan anggota-anggota lainnya. Menurut Gerald (1989) komunikasi interpersonal jenis komunikasi yang harmonis serta terjadi dinamika psikologis mendalam pada masing-masing komunikan (Hasanah, 2017). Sudah jelas bagi kita bahwa ujaran hanya merupakan ekspresi dari gagasan-gagasan pribadi seseorang, dan menekankan hubungan-hubungan yang memiliki sifat dua arah, yaitu memberi dan menerima. Dengan demikian jelas bahwa bahasa memegang peranan penting dalam kehidupan manusia. Komunikasi dapat dipandang sebagai suatu perbuatan-perbuatan atau tindakan-tindakan serangkaian unsur-unsur yang mengandung maksud dan tujuan.

Bahasa merupakan simbol yang mewakili ide, gagasan dan perasaan yang ingin diungkapkan (Setyawati, 2016). Bahasa dalam masyarakat atau dalam suatu kelompok sosial terdapat kekhasan bahasa. Kekhasan bahasa dalam suatu kelompok sosial ada yang bersifat tertutup. Artinya ada kodekode linguistik tertentu yang hanya dapat dipahami oleh anggota kelompok sosial masyarakat yang sama. Contohnya, kelompok sosial waria di Salon Sandra Jalan Jawa Jember. Anggota kelompok sosial ini memiliki istilah khusus tersebut umumnya untuk menghindar dari kemungkinan pemahaman dari orang lain yang bukan anggota kelompok.

Selama ini kelompok waria dipandang hina oleh masyarakat. Oleh karena itu, maka para waria menciptakan sebuah bahasa yang hanya bisa dimengerti oleh kelompok waria saja. Identitas diri, perilaku, dan cara berkomunikasinya bersifat rahasia dengan bahasa khusus atau rahasia. Terbukti istilah-istilah khusus itu dominan untuk melambangkan berbagai konsep tindak tutur yang berkaitan dengan aktivitas mereka yang kebanyakan bernuansa porno. Jadi ketertutupan dan kerahasiaan bahasa waria pada dasarnya merupakan refleksi perilaku kehidupan para waria yang belum diterima oleh masyarakat secara luas. Status waria tergolong status sosial tersendiri berusaha menampakkan identitas dirinya melalui bahasa. Akhirnya terciptalah kode-kode bahasa khusus yang mereka sepakati dan hanya berlaku bagi anggota kelompok sosialnya di salon Sandra Jember. Kode-kode bahasa yang mereka ciptakan sangat bervariasi dan sulit dipahami oleh masyarakat di luar anggota kelompoknya. Artinya, kode bahasa tersebut bersifat rahasia dan tertutup. Bahasa rahasia ini disebut jargon (Hartman and Stark, 1972).

Berdasarkan uraian tersebut, dipandang perlu dan menarik dilakukan penelitian tentang bahasa dan variasi bahasa yang digunakan sebagai alat komunikasi dalam kegiatan interaksi suatu kelompok sosial masyarakat tertentu. Oleh karena itu, penelitian ini diberi judul "Jargon dalam Tindak Tutur Waria Pekerja Salon Sandra Jalan Jawa Jember dalam Interaksi Sosial”. 


\section{JGI: JURNAL GURU INDONESIA}

2021, 1(1), hlm. 34 - 42

https://jurnal.ppjb-sip.org/index.php/jgi/index

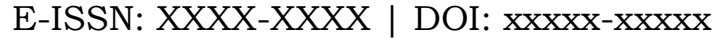

\section{Metode penelitian}

Pendekatan dalam penelitian Jargon dalam Tindak Tutur Waria Pekerja Salon Sandra Jalan Jawa Jember adalah menggunakan pragmatik, yang merupakan kajian bahasa yang berorientasi pada kegunaan bahasa bagi penggunanya. Djajasudarma (2010) mengemukakan bahwa metode penelitian ini memiliki tujuan untuk membuat suatu gambaran atau lukisan secara sistematis, faktual dan akurat seputar data yang sedang diteliti beserta sifat dan hubungan fenomenanya.

Penelitian ini menggunakan metode deskriptif karena tujuan yang hendak dicapai sehubungan dengan topik. Penelitian ini menjelaskan atau memberikan paparan perihal Jargon dalam Tindak Tutur Waria Pekerja Salon Sandra Jalan Jawa Jember dalam Interaksi Sosial. Hal ini senada dengan yang dikatakan oleh Djajasudarma (2010), ia mengatakan bahwa deskripsi merupakan gambaran ciri-ciri data secara akurat sesuai dengan sifat alamiah data itu sendiri. Paparan dan deskripsi dalam penelitian ini terbagi menjadi empat bagian yaitu (1)bentuk jargon dalam bentuk kata yang dipakai waria pekerja salon Sandra Jalan Jawa Jember, 2) wujud jargon dalam bentuk singkatan atau akronim yang dipakai oleh waria pekerja salon Sandra Jalan Jawa Jember, 3) wujud jargon dalam bentuk kalimat yang dipakai waria pekerja salon Sandra Jalan Jawa Jember, 4) Mendeskripsikan fungsi jargon dalam bentuk kata, singkatan atau akronim dan kalimat yang dipakai oleh waria pekerja salon Sandra Jalan Jawa Jember?

Penelitian ini juga menggunakan metode kualitatif. Karena penelitian ini bukan berupa angka angka sebagai variabel, tetapi berupa kualitas bentuk verbal yang berwujud tuturan (Muhajir,1996). Tuturan yang menjadi data penelitian ini adalah Jargon dalam tindak tutur waria pekerja salon Sandra Jalan Jawa Jember dalam interaksi sosial. Data verbal yang berupa catatan tentang jargon berbentuk kata, akronim, dan kalimat ini pun tidak dijadikan angka sehingga tidak diperlukan penghitungan secara statistik. Pendapat Muhajir ini selaras dengan Arikunto (2002) yang menyatakan bahwa penelitian kualitatif merupakan penelitian deskriptif karena penelitian ini berusaha menggambarkan data dengan kata-kata atau kalimat yang dipisahkan menurut kategori untuk memperoleh simpulan.

Untuk melengkapi bahan pembahasan dalam penelitian ini, peneliti mendata jargon berupa kata, akronim, singkatan, dan kalimat yang digunakan oleh para waria pekerja salon Sandra Jalan Jawa Jember.Data tersebut didapat tidak sekaligus dalam jumlah yang banyak melainkan secara bertahap. Hal ini sesuai dengan hasil kegiatan wawancara yang dilakukan oleh peneliti.

Observasi yang dilakukan sekaligus wawancara dengan waria pekerja salon Sandra jalan Jawa Jember dan hasilnya dianalisis berbentuk deskripsi yang tidak berupa angka-angka. Data empiris berupa jargon yang digunakan oleh para waria pekerja salon Sandra jalan Jawa Jember. Selanjutnya data tersebut dicari maknanya dengan menanyakan kepada waria yang sedang berkomomunikasi saat itu.Dengan kata lain sumber data dari penelitian ini adalah waria pekerja salon Sandra jalan Jawa Jember adalah data mentah yang masih harus dianalisis. Sejalan dengan ini Bogdan dan Biklen (1982) menyatakan bahwa penelitian mengacu pada materi mentah yang dikumpulkan peneliti dari dunia yang sedang diteliti, berupa fakta yang digunakan sebagai landasan analisis. Data berupa rekaman/catatan peneliti, seperti transkrip wawancara dan catatan lapangan observasi.

Sejalan dengan ini Bogdan dan Biklen (1982) menyatakan bahwa penelitian mengacu pada materi mentah yang dikumpulkan peneliti dari dunia yang sedang diteliti, berupa fakta yang digunakan sebagai landasan analisis.Data berupa rekaman/catatan peneliti, seperti transkrip wawancara dan catatan lapangan observasi. berisi (1) gambaran/penjelasan yang berupa catatan subjek, rekonstruksi dialog, deskripsi latar fisik, laporan peristiwa khusus, deskripsi kegiatan, dan catatan perilaku peneliti, dan (2) refleksi yang berupa refleksi analisis, refleksi metode, refleksi dilemma dan konflik etika, refleksi kerangka pikir, dan butir-butir penjelasan.

Teknik pengambilan data pada penelitian ini adalah observasi langsung (simak) dan cakap dengan menggunakan alat rekam suara (tape recorder). Metode simak menggunakan teknik simak. Akan tetapi karena para waria yang menjadi narasumber tidak berkenan untuk direkam maka hal ini 
tidak dilakukan oleh peneliti. Jika itu dipaksa dilakukan maka peneliti tidak akan dilayani mengadakan wawancara, sehingga data dicatat dan kemudian dianalisis.

\section{Hasil Penelitian dan Pembahasan}

Seperti dijelaskan sebelumnya bahwa paparan dan deskripsi dalam penelitian ini terbagi menjadi empat bagian yaitu 1) bentuk jargon dalam bentuk kata yang dipakai waria pekerja salon Sandra Jalan Jawa Jember, 2) wujud jargon dalam bentuk singkatan atau akronim yang dipakai oleh waria pekerja salon Sandra Jalan Jawa Jember, 3) wujud jargon dalam bentuk kalimat yang dipakai waria pekerja salon Sandra Jalan Jawa Jember, 4) mendeskripsikan fungsi jargon dalam bentuk kata, singkatan atau akronim dan kalimat yang dipakai oleh waria pekerja salon Sandra Jalan Jawa Jember? Berdasarkan pendataan dalam penelitian ini, dapat dijelaskan bagaimana wujud dan fungsi jargon dalam tindak tutur yang digunakan oleh para waria pekerja salon Sandra jalan Jawa Jember dalam interaksi sosial, dan siapa saja nama-nama waria pengguna jargon tersebut. Daftar waria pengguna jargon, jargon, dan penggunaan jargon adalah sebagai berikut.

Tabel 1.

Waria Pengguna Jargon

\begin{tabular}{|c|c|c|c|c|c|c|c|}
\hline \multirow{2}{*}{ No. } & \multicolumn{2}{|c|}{ Nama } & \multirow{2}{*}{ Usia } & \multirow{2}{*}{ Pekerjaan } & \multirow{2}{*}{$\begin{array}{l}\text { Pendi } \\
\text { di } \\
\text { Kan }\end{array}$} & \multirow{2}{*}{$\begin{array}{l}\text { Alasan Jadi } \\
\text { Waria }\end{array}$} & \multirow[b]{2}{*}{ Jadi Waria Sejak } \\
\hline & Asli & Panggilan & & & & & \\
\hline 1. & Ags & Agnes & 28 thn & Capster & SMA & $\begin{array}{ll}\text { Dari } & \text { diri } \\
\text { sendiri }\end{array}$ & Sejak kecil \\
\hline 2. & $\mathrm{Al}$ & Aliza Moza & 31 thn & Hairstylist & SMP & Suka-suka & Waktu sekolah \\
\hline 3. & Alm & Cheny & 25 thn & Hair Stylist & SD & Takdir & Lulus sekolah \\
\hline 4. & Ant & Tatik & 29 thn & Kapster & SMP & Iseng & Lulus sekolah \\
\hline 5. & Ddk & Dinda & 34 thn & Hair Stylist & SMA & Takdir Ilahi & Sejak kecil \\
\hline 6. & Ek & Echa & 21 thn & Karyawan & SMP & $\begin{array}{l}\text { Stres karena } \\
\text { laki-laki }\end{array}$ & SMP \\
\hline 7. & Ind & Indah & 30 thn & Hairstylist & SMA & Tidak tahu & Umur 29 thn \\
\hline 8. & Lkm & Lucky & 22 thn & Kasir 1 & SMA & Senang tampil & Waktu sekolah \\
\hline 9. & Mnw & Bintang & 24 thn & Karyawan & SMA & Takdir & Lulus sekolah \\
\hline 10. & Mtn & Misse & 35 thn & Pembantu & SD & $\begin{array}{l}\text { Tuntutan } \\
\text { peran }\end{array}$ & Sejak kecil \\
\hline 11. & Mucht & Tari & 25 thn & Karyawan & SD & Karena takdir & SD \\
\hline 12. & Nng & Anggik & 30 thn & Karyawan & SMA & $\begin{array}{l}\text { Dari diri } \\
\text { sendiri }\end{array}$ & Sejak kecil \\
\hline 13. & Par & Peggy & 25 thn & Kasir 2 & SMA & Hobi & Waktu sekolah \\
\hline 14. & Roh & Ima & 41 thn & Kapster & SD & Takdir & Sejak kecil \\
\hline 15. & Sla & Sella & 39 thn & Ngamen & SD & Suratan takdir & Sejak kecil \\
\hline 16. & Tys & Sandra & 31 thn & Capster & SMA & Pelampiasan & SMP \\
\hline 17 & Vnd & Vindi & 19 thn & Karyawan & SMA & Suka dari kecil & Sejak kecil \\
\hline
\end{tabular}

Waria yang terdaftar dalam tabel merupakan anggota Wagayo yang sehari-harinya selalu berkumpul. Wagayo adalah sebuah singkatan dari Waria Gay Organisation. Organisasi ini mewadahi para waria yang ada di Jember yang jumlah anggotanya menurut Ketua Wagayo (Ima) lebih dari 200 orang. 


\section{JGI: JURNAL GURU INDONESIA}

2021, 1(1), hlm. 34 - 42

https://jurnal.ppjb-sip.org/index.php/jgi/index

E-ISSN: XXXX-XXXX | DOI: $\mathrm{xxxxx-xxxxx}$

\section{Bahasa yang Digunakan Waria Pekerja Salon Sandra}

Sebagaimana dijelaskan pada bab sebelumnya bahwa jargon digunakan secara terbatas oleh kelompok tertentu yang sifatnya rahasia. Keterbatasan dan kerahasiaan itu salah satunya disebabkan karena kelompok pemakai jargon memiliki keberbedaan dengan kelompok pemakai bahasa non jargon atau bahasa pada umumnya. Perbedaan itu misalnya tentang fisik, tingkah laku, ataupun strata mereka dalam masyarakat.

Jargon waria pekerja salon Sandra Jalan Jawa Jember memiliki ciri khas yang tidak dimiliki oleh bahasa lain atau bahasa yang dipakai oleh masyarakat umum.Sesuai dengan rumusan masalah dan tujuan penelitian ini, maka berikut dijelaskan data mengenai bahasa yang digunakan oleh para waria yang bekerja di Salon Sandra Jalan Jawa Jember yang diperoleh melalui beberapa cara.

\section{Jargon dalam Bentuk Kata}

Jargon waria pekerja salon Sandra Jalan Jawa Jember memiliki perbedaan dibanding bahasa pada umumnya atau dengan kata lain memiliki ciri khusus. Jargon dalam bentuk kata, akronim atau singkatan, dan jargon bentuk kalimat yang digunakan oleh waria pekerja salon Sandra Jalan Jawa Jember tidak lazim seperti bahasa yang dipakai oleh masyarakat umum. Ketidaklaziman itu dikarenakan makna yang terkandung di dalam jargon itu sama sekali berbeda dengan makna kata yang biasa dikenal oleh masyarakat di luar pemakai jargon. Misalnya jargon akika, cumi-cumi, Diana, Endang, ember, gilingan, Hamidah, jali-jali, mukadimah, nanda, Naspro, organ, organ tunggal, Panasonic, pertiwi, rambutan, sastra, kencana, lapangan bola, Soraya Peruca, memiliki makna yang berbeda dengan makna yang sebenarnya. Misalnya jargon Mataram yang dalam bahasa sehari-hari berarti nama kota di Nusa Tenggara, oleh waria pekerja salon Sandra dijadikan jargon yang maknanya mati. Begitu juga kata Naspro yang dikenal sebagai merek obat sakit kepala, dalam jargon bermakna nasi. Dengan demikian jelas bahwa makna kata berbentuk jargon jauh berbeda dengan makna kata yang sebenarnya.

Jargon berbentuk kata amat sering digunakan para waria di dalam berkomunikasi dengan sesama waria. Kata-kata itu diungkapkannya dengan maksud dan tujuan tertentu terutama untuk menyembunyikan masalah yang sebenarnya. Jargon berbentuk kata digabung dengan kata yang biasa digunakan oleh masyarakat pada umumnya. Tetapi kadang secara keseluruhan terdiri dari kata-kata yang berbentuk jargon.Contohnya kata mabarina digunakan saat salah satu waria ditanya tentang keadaan waria lainnya. Hal ini dapat digambarkan dalam cuplikan dialog mereka.

Berikut diuraikan kutipan beberapa dialog terutama dialog yang berkaitan dengan masalah-masalah yang bersifat porno atau tabu untuk diketahui oleh orang lain selain waria. Hal ini berkaitan dengan alasan mengapa para waria menggunakan jargon dalam berkomunikasi dengan waria lainnya.

(1) "Siapa mabarina”. Maksudnya siapa mabuk. Kata mabarina dalam kalimat (1) yang berarti mabuk akan menimbulkan kesan negatif pada pelanggan karena pelanggan mengerti maksud pembicaraan mereka. Oleh karena itu, mereka menggunakan kata mabarina agar pelanggan tidak paham dan tidak mengecap jelek pada pembicara. Begitu juga kata cumi-cumi yang artinya cium-cium.

(2) "Luky itu terlalu banyak cumi-cumi, sih. (3) Makanya mabarina." Maksud kalimat (2) adalah Luky terlalu banyak cium-cium, sih. Makanya mabuk Kalimat (3) Kalimat itu (2) dan (3) akan berbeda kesannya jika diucapkan seperti yang biasa diucapkan oleh masyarakat pada umumnya. Kalimat "Luky terlalu banyak cium-cium, sih. Makanya Luky mabuk," adalah kalimat yang sangat tabu untuk diucapkan di depan orang lain dan bahkan menimbulkan kesan jorok. Untuk itu waria menggunakan jargon agar rahasianya tidak diketahui oleh pelanggan. Pelanggan mengira bahwa cumi-cumi yang dimaksud dalam kalimat itu benar-benar cumi-cumi. Kata Endang yang berarti enak akan menimbulkan kesan jelek juga bila diucapkan enak. 
(4) "Tadi malam asyik deh pokoknya. Cumi-cumi biasa kayak di sinetron itu."

(5) “Gimana rasa cumi-cuminya? Atau "Gimana cium-ciumnya?"

(6) "Ya Endang, sih."Maksudnya ya enak, sih."Jawaban ini diucapkannya dengan sedikit berbisik karena takut tertebak oleh pelanggan.

(7) "Gilingan kanua." Artinya Gila kamu.Mungkin mendengar kalimat itu, pelanggan mengira bahwa yang dimaksud oleh mereka bahwa mereka kebanyakan makan cumi-cumi hingga disamakan dengan gilingan.Sedang kata kanua dalam kalimat (7) bisa dipersepsikan dengan merek barang. Kata mandole, Mataram, atau metong, dan merekah digunakan waria untuk memperbincangkan sesuatu yang telah dilakukan oleh waria yang sifatnya mengecewakan.

(8) “Loh, kenapa kok sampai Mataram? (9) Apa gak merekah dia?" Maksudnya kalimat (8) "Loh kenapa kok sampai mati?"Kalimat (9) maksudnya "Gak marah dia?" Mati yang dimaksud dalam pembicaraan itu (8) adalah alat kelamin laki-laki yang mengencaninya. Kalau hal ini diungkapkannya dengan bahasa yang sama seperti bahasa masyarakat pada umumnya, pastilah menimbulkan masalah sehingga identitas mereka diketahui dan akhirnya bisa menyebabkan pelanggan tidak mau kembali lagi. Lambreta yang berarti lambat juga digunakan mereka dalam hal yang bersifat porno.

(10) "Aku suka gerakan lambreta." Maksudnya "Aku suka gerakan lambat."Gerakan lambat yang dimaksud oleh adalah gerakan lambat lelaki yang mengencaninya. Dengan begitu pelanggan mungkin bisa mengira bahwa dia suka dengan gerakan seseorang yang bernama Lambreta.

(11) "Aku dibayar Maharani." Artinya "Aku dibayar mahal. "Maksud pembicaraan itu bahwa Si waria dibayar mahal setelah melakukan kencan dengan teman laki-lakinya. Sedang pelanggan bisa mengira maksudnya adalah "Aku dibayar mahal oleh Maharani. Kata-kata yang berbentuk jargon digabungkan dengan kata-kata yang umumnya dipakai oleh masyarakat di luar kelompok waria. Mereka menggunakan jargon dalam kalimat yang tidak menimbulkan kecurigaan pada yang mendengarnya atau pada pelanggannya. Penggabungannya rupanya telah dipikirkan sebelumnya agar yang mendengar tidak mengira ada hal-hal yang tabu ataupun porno. Hamidah yang dalam kehidupan sehari-hari merupakan nama orang, oleh waria dijadikan jargon yang berarti hamil. Kata Hamidah muncul dari percakapan mereka saat mereka membicarakan teman perempuannya. Salah satu teman perempuannya sudah lama tidak datang ke salon itu.Kemudian mereka mengatakan dengan asal ceplos saja.

(12) "Reni ke mana, sih. Kok gak pernah nongol.Aku dah kangen ama dia. Mungkin ada dua minggu gak ke sini."

(13) "Hamidah kali..." Maksudnya "Hamil mungkin."

Jargon berupa kata digunakan oleh para waria pekerja salon Sandra jalan Jawa Jember kebanyakan tidak berdiri sendiri melainkan digabung dengan kata yang sudah lazim digunakan oleh masyarakat pada umumnya. Tetapi terkadang mereka menggunakan hanya dalam satu kata (jargon) saat menjawab pertanyaan temannya. Kalimat penutur yang berbunyi (14) "Loh, kenapa kok sampai Mataram?

(15) Apa gak merekah dia?"Kata yang berupa jargon dalam kalimat (14) hanyalah Mataram dan merekah dalam kalimat (15). Jadi penggunaan jargon tidak selalu berbentuk jargon semuanya dalam kalimat.Hal itu dilakukan oleh penutur karena walau orang lain yang bukan kelompoknya mendengar ucapan mereka, mereka yakin orang tersebut tidak mengerti.

\section{Jargon dalam Bentuk Singkatan dan Akronim}

Selain berbentuk kata, jargon yang digunakan oleh waria pekerja Salon Sandra ada yang berbentuk singkatan dan akronim, akan tetapi jumlahnya tidak banyak. Apa sebabnya tidak diketahui 


\section{JGI: JURNAL GURU INDONESIA}

2021, 1(1), hlm. 34 - 42

https://jurnal.ppjb-sip.org/index.php/igi/index

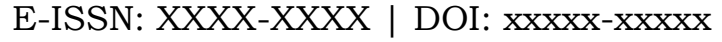

karena ketika narasumber ditanya, hanya menjawab dengan "Gak tahu". Singkatan dan akronim yang dimaksud adalah sebagai berikut.

1. Titi DJ = Hati-hati di jalan: akronim

Kalimat ini diucapkan saat ada salah satu temannya keluar dari salon karena ada kepentingan di tempat lain.

\section{EGPCC= Emang Gue Pikirin Cuih cuih (singkatan)}

Singkatan tersebut digunakan oleh waria tidak digabung dengan kata atau jargon lainnya dan berdiri sendiri.Singkatan EGPCC hanya digunakan untuk menjawab sebagai ungkapan ekspresi ketidakpedulian, kekecewaan, ataupun ungkapan kekesalan penutur.Ketika salah seorang dari mereka menanyakan sesuatu atau mengungkapkan suatu berita, maka dijawab EGPCC.Hal ini terlihat dalam kutipan percakapan antara Im dan Ttk.

(16) Ke mana peconganmu kok gak nongol-nongol dari tadi? Maksudnya ke mana pacarmu kok tidak kelihatan dari tadi.

(17) EGPCC artinya Emang Gue Pikirin Cuih-Cuih.

Bila ada cerita yang menurutnya tidak menarik untuk ditanggapi atau sesuatu yang menjengkelkan maka singkatan tersebut muncul dari mulut mereka dengan ekspresi kurang senang.

\section{3. $\mathrm{SDMB}=$ sori dori mori bow : singkatan}

Ungkapan ini timbul sebagai bentuk pernyataan menolak ataupun permintaan maaf bahkan sebagai ekspresi kejengkelan penutur saat mereka diolok-olok oleh temannya.

\section{LUPUS = Lupain Pacar Utamakan Selingkuh (singkatan)}

Kalimat ini biasanya dilontarkan sambil bergurau untuk memberi saran bila teman waria lainnya curhat mengenai pria idamannya.

Jargon berbentuk singkatan dan akronim tidak terlalu banyak. Singkatan dan akronim yang dijadikan jargon adalah singkatan ataupun akronim yang tidak dikenal oleh masyarakat umum yang bukan pemakai jargon. Misalnya Titi DJ adalah nama artis penyanyi terkenal. Akronim tersebut memang bisa ditebak apa maksud penuturnya sebab biasanya diungkapkan saat memberi peringatan kepada temannya yang berpamitan untuk keluar. Kalimat (18) Titi Dj ya, yang kemudian direspon oleh waria yang sedang berpamitan keluar itu dengan ya. Ucapan penutur walau terdengar jelas oleh orang lain tidak akan menimbulkan masalah. Dan tentu saja orang lain bisa menebak apa maksudnya. Peneliti sendiri merasa tidak kesulitan menebak maknanya. Dan biasanya diucapkan dengan nada agak keras. Jadi penutur tidak mempermasalahkan bila orang lain mendengar bahkan mengerti maksudnya karena hal itu tidak berpengaruh jelek pada mereka, justru akan sebaliknya karena orang lain akan memujinya karena telah mengingatkan temannya agar berhati-hati di jalan.

Akronim Lupus juga digunakan waria. Lupus yang artinya Lupain Pacar Utamakan Selingkuh diungkapkan waria saat mereka bercanda dan bercerita tentang kegiatan mereka yang berkaitan dengan masalah pacaran. Mereka dengan tanpa peduli mengucapkan akronim itu karena mereka yakin bahwa orang lain pasti tidak mengerti.

Lain halnya dengan singkatan EGPCC. Orang lain bisa dipastikan tidak memahami apa maksudnya sebab singkatan tersebut tidak lazim di dalam kehidupan sehari-hari. Orang lain hanya diam dan tidak bersikap apapun karena memang tidak mengerti. Singkatan EGPCC adalah singkatan yang di dalam kehidupan sehari-hari tidak pernah dijumpai.Singkatan itu diciptakan dengan 
menggabungkan setiap huruf awal kata yang sebenarnya. Dan jargon ini sangat sering diucapkan karena di dalam percakapan mereka sering terjadi saling olok. SDMB juga merupakan singkatan yang tidak lazim di kalangan masyarakat umum. SDMB atau sori dori mori bow terdiri dari katadori dan mori yang merupakan kata tidak bermakna dalam masyarakat akan tetapi digunakan sebagai jargon di kalangan waria pekerja salon Sandra jalan Jawa Jember.

\section{Jargon Berbentuk Kalimat}

Jargon berbentuk kata, singkatan, dan akronim, selanjutnya oleh waria pekerja Salon Sandra digabung menjadi kalimat yang sesuai dengan konteksnya. Mereka dengan sangat lancar menggabung kata demi kata menjadi sebuah kalimat.Hal ini terjadi karena ternyata mereka telah hafal kata-kata ataupun singkatan dan akronim yang mereka ciptakan sendiri. Kalimat-kalimat yang dapat didata oleh peneliti ada beberapa kalimat yaitu:

(19) Lekong yang aku godog jogja tuh cakabirawa.

Artinya "Lelaki yang aku goda itu cakep banget."Kalimat (19) diucapkan waria saat menceritakan pengalamannya bahwa dia telah berhasil menggoda seorang laki-laki yang menurutnya laki-laki itu tampan (cakep).

Akika mau capcus deh, masak dari kemarin gak belenjong makarena. Kalimat (20) ini diucapkan oleh waria saat santai dan mereka butuh makanan karena di tempat mereka berkumpul sedang tidak ada makanan ringan.

(21) Diana abis dicumi pecongnya. Idih, ngeri deh.

Artinya "Dia habis dicium pacarnya. Idih ngeri deh. "Kalimat (21) adalah ungkapan yang dilontarkan salah satu waria mengenai rekannya yang melakukan adegan ciuman dengan laki-laki yang mengencaninya.

Akika mau beranak dalam kubur dulu ya, aduh sakitnya setengah metong, nih. Artinya "Aku mau berak dahulu ya, aduh sakitnya setengah mati, nih." Waria yang mengucapkan kalimat (22) mengeluh sedang sakit perut dan berpamitan untuk mau buang air besar.

Huh, kok Panasonic, sih. Ac-nya dinyalakan opoo sih rek.

Artinya "Huh, kok panas sih. Ac-nya dinyalakan kenapa, sih." Kalimat (23) mudah ditebak karena saat pembicara mengungkapkannya di ruangan itu terasa panas sehingga kata Panasonic dalam kalimat (23) bisa dipahami dengan mudah oleh orang lain (pelanggan).

\section{Simpulan}

Jargon digunakan oleh para waria pekerja salon Sandra jalan Jawa Jember bertujuan selain untuk berkomunikasi antarwaria juga untuk menutupi rahasia mengenai aktivitas mereka yang cenderung menyimpang. Jargon memiliki makna yang menyimpang dari makna yang sebenarnya dan tidak seperti yang dipahami dan digunakan oleh masyarakat umum.

\section{Daftar Pustaka}

Arifin, Anwar. 1995. Ilmu Komunikasi, Jakarta: PT Raja Grafindo Persada.

Hartman \& Stork. (1972). "Dictionary of language and lingusistics.

Djajasudarma, F. (2010). Metode Linguistik: Ancangan Metode Penelitian dan Kajian. Bandung: PT Refika Aditama.

Muhadjir, Noeng. (1996). Metode Penelitian Kualitatif. Rake Sarasin: Yogyakarta.

Arikunto, S. 2002. Metodologi Penelitian Suatu Pendekatan Proposal. Jakarta: PT. Rineka Cipta.

Bogdan, R.C., Biklen, S.K.1982. Qualitative research for education: anintroduction to theory and method. Boston: Allyn and Bacon. Inc 


\section{JGI: JURNAL GURU INDONESIA}

2021, 1(1), hlm. 34 - 42

https://jurnal.ppjb-sip.org/index.php/igi/index

E-ISSN: XXXX-XXXX | DOI: $\mathrm{xxxxx-xxxxx}$

Hasanah, H. (2017). Pengaruh Komunikasi Interpersonal Dalam Menurunkan Problem Tekanan Emosi

Berbasis Gender. Sawwa: Jurnal Studi Gender, 11(1), 51. https://doi.org/10.21580/sa.v11i1.1446 Inah Ety, N. (2013). PERANAN KOMUNIKASI DALAM PENDIDIKAN. 6(1), 176-188.

Setyawati, N. (2016). Pemakaian Bahasa Gaul Dalam Komunikasi Di Jejaring Sosial. Pemakaian Bahasa Gaul Dalam Komunikasi Di Jejaring Sosial, c, 1-28. download.portalgaruda.org 